\title{
Estimated assessment of cumulative dietary exposure to organophosphorus residues from tea infusion in China
}

\author{
Pei Cao ${ }^{1,2}$, Dajin Yang ${ }^{2}$, Jianghui Zhu², Zhaoping Liu², Dingguo Jiang ${ }^{2}$ and Haibin $\mathrm{Xu}^{2^{*}}$
}

\begin{abstract}
Background: China has the world's largest tea plantation area in the world. To sustain high yields of the tea, multiple pesticides are used on tea crops to control pests. Organophosphorus (OP) pesticides are among the most widely used types of agricultural pesticides in China. As tea is a significant potential source of exposure to pesticide residues, the public concern has increased in relation to pesticide residues found in tea in China. The aim of the study was to estimate cumulative dietary exposure to OP residues from tea infusion for Chinese tea consumers to determine whether exposure to OP residues from tea infusion is a cause of health concern for tea consumers in China.

Methods: OP residue data were obtained from the China National Monitoring Program on Food Safety (2013-2014), encompassing 1687 tea samples from 12 provinces. Tea consumption data were obtained from the China National Nutrient and Health Survey (2002), comprising 506 tea consumers aged 15-82 years. The transfer rates of residues from tea leaves into tea infusions were obtained from the literature. The relative potency factor (RPF) approach was used to estimate acute cumulative exposure to $20 \mathrm{OP}$ residues from tea infusion using methamidophos as the index compound. Dietary exposure was calculated in a probabilistic way.

Results: For tea consumers, the mean and the 99.9th percentile (P99.9) of cumulative dietary exposure to OP residues from tea infusion equalled 0.08 and $1.08 \mu \mathrm{g} / \mathrm{kg} \mathrm{bw} / \mathrm{d}$. When compared with the acute reference dose (ARfD), $10 \mu \mathrm{g} / \mathrm{kg} \mathrm{bw} / \mathrm{d}$ for methamidophos, this accounts for 0.8 and $10.8 \%$ of the ARfD.

Conclusions: Even when considering OP residues from vegetables, fruits and other foods, there are no health concerns based on acute dietary exposure to OP residues from tea infusion. However, it is necessary to strengthen the management of the OP pesticides used on tea in China to reduce the risk of chronic dietary exposure to OPs from tea infusion.
\end{abstract}

Keywords: Organophosphorus residues, Cumulative dietary exposure, Risk assessment, Tea infusion

\section{Background}

For almost 4000 years, tea has been prepared by processing the leaves of the Camellia sinensis plant for consumption in the form of an infusion [1,2]. China has one of the world's longest histories of tea production. Depending on how the leaves are processed, three main types of tea can be produced: non-fermented tea, e.g. green tea; semi-fermented tea, e.g. oolong tea; and fermented tea, e.g. black tea [3]. Tea leaves have been found to contain compounds beneficial to human health,

\footnotetext{
* Correspondence: hbxu1231602@cfsa.net.cn

${ }^{2}$ Risk Assessment of Division One, China National Center for Food Safety Risk Assessment, No 37, Building 2, Guangqu Road, Chaoyang District, Beijing 100021, China

Full list of author information is available at the end of the article
}

such as polyphenols $[4,5]$. However, tea leaves may also contain hazardous compounds, such as pesticide residues and mycotoxins [6]. China has the world's largest tea plantation area and is the second largest tea exporter in the world [7-9]; it exported tea to more than 140 countries from 2005 to 2009 [8, 10]. More and more people around the world are consuming tea because of its beneficial health effects. Clearly, tea is one of the most popular beverages in the world, especially in Asia. Accordingly, the production of tea in China in 2014 totalled 209.2 million tons, an increase of $10.33 \%$ over 2013; this accounted for $41.6 \%$ of total global production [11]. To sustain such high yields and to ensure the quality of the tea, multiple pesticides are used on tea crops 
to control pests [12]. Organophosphorus pesticides (OPs) are among the most widely used types of agricultural pesticides in China, owing to their broad-spectrum insecticidal activity, high effectiveness and low cost [13].Some studies have found that a few high toxicity OPs are frequently detected on tea crops in China, although approximately $70 \%$ of OPs have been banned due to their high toxicity [14-17].Some old pesticides are still used illegally on tea crops, and tea has a shorter interval between pesticide treatment and harvest compared with other crops [18]. Therefore, tea is a significant potential source of exposure to pesticide residues, particularly among extreme tea consumers (those who consume very high amounts of tea).Thus, public concern has increased in relation to pesticide residues found in tea in China [19-22]. To address this concern, it has become necessary to monitor pesticide residues in tea and to estimate the potential intake of these pesticides.

Conventional approaches to assessing dietary exposure to contaminants and additives in food are deterministic, using point estimates for consumption and contamination [23]. Point estimates are widely used in dietary exposure assessments of pesticide residues in food, as they are simple and accessible [24]. However, they have the obvious limitations of being unrealistic and less informative $[25,26]$. The probabilistic approach, in contrast, takes into consideration the uncertainty and variability of exposure and also provides a distribution outcome [27]. It is considered a useful technique for performing acute dietary exposure estimates of pesticide residues [27]. Thus, in some countries and in international organisations, the national registration process for contaminants and additives also includes the probabilistic approach [28].

People are exposed to more than one pesticide through the consumption of tea because tea may contain more than one type of residue [15-17, 29, 30]. Previous dietary exposure assessments of pesticide residues in tea have usually been performed separately for individual pesticides $[19,21,22]$. If these chemicals have the same mode of toxicological action, the traditional method of separately assessing dietary exposure to pesticides may underestimate the health risk [31]. To address dietary exposure to such chemicals, individual exposures should be addressed together. Cumulative exposure assessment is applicable and suitable for assessing the cumulative toxicological effect, which is assumed to be equal to the sum of chemicals' individual effects if there are no synergistic or antagonistic effects [32, 33]. To calculate the cumulative dietary exposure to OPs, the relative potency factor (RPF) approach was applied in this assessment.

Cumulative dietary exposure assessment to $\mathrm{OP}$ residues has been performed in some countries, such as the USA, the Netherlands and Brazil [26, 31, 34].
Meanwhile, Sun J.F. et al. performed a cumulative risk assessment of dietary exposure to OP residues in China, but the food items in this assessment mainly involved vegetables, fruits and staple food; just two kinds of tea was included [35]. There is no report estimating cumulative exposure to OPs for tea consumers on a nationwide scale in China. The purpose of the present study was to estimate cumulative dietary exposure to OP residues from tea infusion for Chinese tea consumers-using a probabilistic approach and the RPF approach-to determine whether exposure to OP residues from tea infusion is a cause of health concern for tea consumers in China.

\section{Methods}

\section{Pesticide residue data analysis in tea}

Pesticide residue data were obtained from the China National Monitoring Program on Food Safety during 2013-2014. A total of 1687 samples from three types of tea were analysed for 25 OP residues. In this monitoring program, the tea samples were collected from supermarkets and local markets in 12 provinces, including Anhui, Fujian, Sichuan, Hunan, Jiangsu, Guangxi, Hubei, Zhejiang, Yunnan, Xinjiang, Beijing and Guangdong in China. Sample analysis was performed by the Center for Disease Prevention and Control in each province or district of China, according to the national standards (GB/T 5009.20-2003) for the determination of $\mathrm{OP}$ residues in tea. The analytical method for OPs used gas chromatography (GC)-flame photometric detection (FPD) established by the National Health and Family Planning Commission of the People's Republic of China. The limit of detection (LOD) ranged from 0.000011 to $0.22 \mathrm{mg} \mathrm{kg}^{-1}$. The laboratories were certified for quality control in the detection procedure by China National Center for Food Safety Risk Assessment to ensure the accuracy and comparability of the monitoring data from different laboratories.

\section{Tea consumption data}

The tea consumption data were obtained from the China National Nutrient and Health Survey conducted in 2002 [36]. This survey used multistage, random cluster sampling, which was conducted in 132 sampling locations in 31 provinces in China, using three consecutive, 24-h dietary recall face-to-face interviews, including two weekdays and one weekend, holidays excluded. A total of 506 tea consumers aged 15-82 years (of which 280 were male, 226 were female) recorded their tea consumption volume and types of tea consumed over three consecutive days. In addition, in this survey, the age of the tea consumer was almost always above 15 years old, as children generally do not drink tea. Characteristics of each respondent, including age, sex, weight and address, were obtained through questionnaires. 


\section{Relative potency factors}

The RPF approach used the sum of concentrations of various pesticides in the each class after adjustment by RFP. The concentrations of all compounds in a food are expressed as equivalents of one 'index compound' (IC) and summed [37].RPFs were defined as the ratio between the critical effect dose (CED) of the IC and the same of the remaining compounds in this group [26]. The CEDs were also selected from international authoritative institutions, e.g. the US Environmental Protection Agency (EPA) and the Joint Meeting of Pesticide Residues (JMPR). In this study, the critical effect was that of AChE inhibition in the female rat brain after 21 days of exposure; this information was provided by the US EPA. As with most OP pesticides, females appeared to be more sensitive than males [34, 38]. The selection of the IC in a cumulative assessment requires many studies and many toxicological data $[38,39]$. Methamidophos was used as the IC, as it had high-quality data for toxicological action for AChE inhibition; methamidophos has also been detected in tea samples in China [26, 38]. Additional file 1: Table S1 shows that the RPFs were calculated based on the benchmark dose (BMD) at a $10 \%$ AChE reduction in the female rat brain, using methamidophos as the IC.

In addition, Bosgra et al. used the EPA data on AChE inhibition in the female rat brain after 21 days of exposure to fit the dose-response curves [37]. Additional file 1: Table S2 shows that the RPFs were calculated based on CEDs corresponding to $20 \% \mathrm{AChE}$ inhibition by OPs, derived from the fitted curves using methamidophos as the IC. To analyse whether RPFs derived from different critical effect doses will affect the results of cumulative exposure assessment, both of these CEDs will be used in the calculations.

\section{Transfer rate of pesticide residues to tea infusion}

As tea is consumed indirectly, tea infusion is the main route of human exposure to pesticide residues in tea. Several studies have investigated the transfer rates (TRs) of pesticides during tea brewing [21, 40-44]. The TRs of $\mathrm{OP}$ residues from tea leaves into tea infusions were selected from the open scientific literatures, and the details of the TRs of OP residues into tea infusions are shown in Additional file 1: Table S3.

The pesticide residues that were leached into the tea infusion mostly depended on the water solubility and the octanol-water $\left(K_{\mathrm{ow}}\right)$ partition coefficient [45-47]. Wan et al. found that, at low water solubility $(<10 \mathrm{mg} /$ $\mathrm{kg}$ ), the TR was $1-4 \%$ and was not sensitive to variations in water solubility. When the water solubility was within the range of $10-150 \mathrm{mg} / \mathrm{kg}$, the TR was sensitive to water solubility. When the water solubility $>179 \mathrm{mg} / \mathrm{kg}$, the TR $>90 \%$ and no longer sensitive to changes in water solubility [46]. Additional file 1: Table S4 shows the water solubility and $\log \left(K_{\text {ow }}\right)$ of OP residues detected in tea samples. According to water solubility and $\log \left(K_{\text {ow }}\right)$ of OP residues, the OP residues found in tea samples are divided into three categories: soluble pesticides (water solubility $\geq 200 \mathrm{mg} / \mathrm{L}$ ), moderately soluble pesticides (water solubility $10-200 \mathrm{mg} / \mathrm{L}$ ) and low soluble pesticides (water solubility $<10 \mathrm{mg} / \mathrm{L}$ ). Based on the TRs of three types of OP residues obtained from the open scientific literatures, we calculated the median TRs of each type of OP residue to represent the TR of this category. The median TRs of soluble OPs, moderately soluble OPs and low soluble OPs were 87.4, 22.1 and $2.8 \%$, respectively.

\section{Modelling of cumulative dietary exposure}

Acute dietary exposure of Chinese tea consumers to OP residues from tea infusion was calculated in a probabilistic way using a @Risk software (version 6.0, Palisade). The probabilistic modelling software used in this study was implemented by Monte Carlo simulations, which simulated daily consumptions by sampling from the tea consumption distribution and combined these with a random sample from the concentration (the IC equipotent concentrations of OPs adjusted by the corresponding TR in tea infusion) distribution. The random sampling from the concentration distribution was according to the rate of the sample with detectable and rate of the sample with undetectable, respectively. Each tea consumer's daily cumulative dietary exposure to OP residues from tea infusion $(\mu \mathrm{g} / \mathrm{kg}$ bw $/ \mathrm{d})$ was calculated by tea consumption combined with the IC equipotent concentrations of OPs in tea infusion on a single day, adjusted by the measured individual body weight of each tea consumer.

The @Risk software was used to fit the concentration data, tea consumption data and body weight data to obtain the appropriate distribution: the lognorm distribution for the IC equipotent concentrations of tea samples above LOD. Considering the uncertainty and variability in the concentrations of undetected samples, the concentrations of undetected tea samples were assumed to have a distribution ranging from 0 to the maximum LOD for OPs $(0.22 \mathrm{mg} / \mathrm{kg})$, also expressed as the IC equivalents. A uniform distribution was assumed for the IC equipotent concentrations of LOD in the case of undetectable samples. The InvGauss distribution was applied to tea consumption data. The normal distribution was used for tea consumers' body weights. The details of the descriptions of variables and models for this dietary exposure assessment are shown in Table 1. The number of Monte Carlo iteration was 100,00 and simulation was 200. The exposures were specified at percentiles P50, P90, P95, P97.5, P99 and P99.9 and mean from the intake distribution, and compared with the 
Table 1 Description and distribution of variables and models for dietary exposure assessment of OP residues in tea infusion

\begin{tabular}{|c|c|c|c|c|}
\hline Compound & Variables & Definition & Assumption/distribution/formula & Source \\
\hline \multirow[t]{26}{*}{ OPs } & \multirow[t]{3}{*}{ Conc $_{Q p}$} & \multirow{3}{*}{$\begin{array}{l}\text { Concentration in methamidophos } \\
\text { equivalents of OPs in tea infusion } \\
\text { (detected value) }\end{array}$} & Lognorm $(0.052,4.636)^{a}$ & \multirow[t]{3}{*}{ Monitoring data } \\
\hline & & & Lognorm $(0.003,0.041)^{\mathrm{b}}$ & \\
\hline & & & Lognorm $(0.003,0.151)^{c}$ & \\
\hline & \multirow[t]{3}{*}{ Conc $_{Q n}$} & \multirow{3}{*}{$\begin{array}{l}\text { Concentration in methamidophos } \\
\text { equivalents of OPs in tea infusion } \\
\text { (undetected value) }\end{array}$} & Uniform $(0,0.105)^{a}$ & \multirow[t]{3}{*}{ Monitoring data } \\
\hline & & & Uniform $(0,0.044)^{b}$ & \\
\hline & & & Uniform $(0,0.105)^{c}$ & \\
\hline & \multirow[t]{3}{*}{$\operatorname{Conc}_{Q p}^{*}$} & \multirow{3}{*}{$\begin{array}{l}\text { Concentrationin in methamidophos } \\
\text { equivalents of OPs in tea infusion } \\
\text { (detected value) }\end{array}$} & Lognorm $(0.038,2.987)^{a}$ & \multirow[t]{3}{*}{ Monitoring data } \\
\hline & & & Lognorm $(0.002,0.019)^{\mathrm{b}}$ & \\
\hline & & & Lognorm $(0.001,0.019)^{c}$ & \\
\hline & \multirow[t]{3}{*}{$\operatorname{Conc}_{Q n}^{*}$} & \multirow{3}{*}{$\begin{array}{l}\text { Concentration in methamidophos } \\
\text { equivalents of OPs in tea infusion } \\
\text { (undetected value) }\end{array}$} & Uniform $(0,0.447)^{a}$ & \multirow[t]{3}{*}{ Monitoring data } \\
\hline & & & Uniform $(0,0.235)^{\mathrm{b}}$ & \\
\hline & & & Uniform $(0,0.447)^{c}$ & \\
\hline & \multirow[t]{3}{*}{$P p$} & \multirow[t]{3}{*}{ Rate of sample with detectable } & $10.11 \%^{\mathrm{a}}$ & \multirow[t]{3}{*}{ Calculated } \\
\hline & & & $13.53 \%^{\mathrm{b}}$ & \\
\hline & & & $6.20 \%^{c}$ & \\
\hline & \multirow[t]{3}{*}{$P n$} & \multirow[t]{3}{*}{ Rate of sample with undetectable } & $89.89 \%^{\mathrm{a}}$ & \multirow[t]{3}{*}{ Calculated } \\
\hline & & & $86.47 \%^{b}$ & \\
\hline & & & $93.80 \%^{\mathrm{c}}$ & \\
\hline & Conc $_{Q C}$ & $\begin{array}{l}\text { Concentration in methamidophos } \\
\text { equivalents of OPs in tea infusion }\end{array}$ & Discrete (ConcQp: ConcQn, Pp: Pn) & Calculated \\
\hline & \multirow[t]{3}{*}{$T R$} & \multirow[t]{3}{*}{ Transfer rate } & $87.4 \%$ & \multirow{3}{*}{$\begin{array}{l}\text { Based on the open scientific literatures } \\
\text { to calculate }\end{array}$} \\
\hline & & & $22.1 \%$ & \\
\hline & & & $2.8 \%$ & \\
\hline & \multirow[t]{3}{*}{ Cons } & \multirow[t]{3}{*}{ The consumption of tea } & Invgauss $(3.772,0.721)^{a}$ & \multirow[t]{3}{*}{ China National Nutrient and Health Survey } \\
\hline & & & Invgauss $(4.474,1.718)^{b}$ & \\
\hline & & & Invgauss $(11.532,10.870)^{c}$ & \\
\hline & $B W$ & Body weight for tea consumers & Normal $(55.1,15.5)$ & China National Nutrient and Health Survey \\
\hline
\end{tabular}

For Conc $_{Q p}$ and Conc $C_{Q n}$ mark with an asterisk $(*)$, RPFs were calculated based on CED at 20\% AChE inhibition in rat brain, IC for OPs is methamidophos For Conc $_{Q p}$ and Conc $_{Q n}$, RPFs were calculated based on BMDat 10\% AChE inhibition in rat brain, IC for OPs is methamidophos

The $87.4,22.1$ and $2.8 \%$ were TRs of soluble OPs, moderately soluble OPs and low soluble OPs, respectively

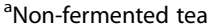

${ }^{\mathrm{b}}$ Semi-fermented tea

${ }^{\mathrm{c}}$ Fermented tea

ARfD of methamidophos, $10 \mu \mathrm{g} / \mathrm{kg}$ bw/d established in 2002 by JMPR [48].

\section{Results}

\section{Residue and food consumption data}

Table 2 summarises the results of the samples analysed, including the positive rates and concentrations of detected samples in tea for all types of OPs. In total, 1687 tea samples were analysed for 25 OP pesticides in the National Monitoring Program. There were 169 positive tea samples tested for 20 OPs, including highly toxic pesticides, e.g. methamidophos, parathion-methyl, parathion, monocrotophos, triazophos; moderately toxic pesticides, e.g. chlorpyrifos, omethoate, dimethoate; and low toxicity pesticides, e.g. acephate and malathion. The total positive rate was $10.02 \%$. Chlorpyrifos $(6.75 \%)$, triazophos $(2.59 \%)$ and disulfoton $(0.74 \%)$ were detected most among the 20 OPs in the tea samples above the LOD. The highest concentration values were found for chlorpyrifos $(1.900 \mathrm{mg} / \mathrm{kg})$, dimethoate $(0.980 \mathrm{mg} / \mathrm{kg})$ and omethoate $(0.930 \mathrm{mg} / \mathrm{kg})$. As the monitored tea samples were found to have less pyridaphethione, diazinon, trichlorfon, quinalphos and phoxim, and the positive rate was 0 , this study included 20 detected OP residues in its cumulative exposure assessment.

As the same tea sample may simultaneously contain more than one type of OP, Table 3 shows the tea samples that were positive for the detection of a number of OPs. Among 169 samples that tested positive for OPs, a total of $129(7.65 \%)$ tea samples contained only one OP, 27 
Table 2 Concentrations of OPs in tea from the 2013-2014 National Monitoring Program

\begin{tabular}{|c|c|c|c|c|c|c|c|c|c|}
\hline \multirow[t]{2}{*}{ OPs } & \multirow{2}{*}{$\begin{array}{l}\text { Samples } \\
\text { analysed }\end{array}$} & \multirow{2}{*}{$\begin{array}{l}\text { Detected } \\
\text { samples }\end{array}$} & \multirow{2}{*}{$\begin{array}{l}\text { Positive } \\
\text { rate (\%) }\end{array}$} & \multicolumn{6}{|c|}{ Concentrations of detected samples in tea (mg/kg) } \\
\hline & & & & Mean & $P_{50}$ & $P_{95}$ & $P_{97.5}$ & $P_{99.9}$ & Max \\
\hline Chlorpyrifos & 1660 & 112 & 6.75 & 0.138 & 0.060 & 0.594 & 0.788 & 1.900 & 1.900 \\
\hline Triazophos & 1619 & 42 & 2.59 & 0.152 & 0.125 & 0.427 & 0.801 & 0.830 & 0.830 \\
\hline Disulfoton & 1623 & 12 & 0.74 & 0.265 & 0.295 & 0.706 & 0.706 & 0.706 & 0.706 \\
\hline Dimethoate & 1642 & 11 & 0.67 & 0.261 & 0.220 & 0.980 & 0.980 & 0.980 & 0.980 \\
\hline Monocrotophos & 1634 & 10 & 0.61 & 0.201 & 0.095 & 0.909 & 0.909 & 0.909 & 0.909 \\
\hline Parathion-methyl & 1646 & 10 & 0.61 & 0.052 & 0.041 & 0.162 & 0.162 & 0.162 & 0.162 \\
\hline Ethion & 1638 & 9 & 0.55 & 0.066 & 0.020 & 0.240 & 0.240 & 0.240 & 0.240 \\
\hline Tolclofos-methyl & 386 & 2 & 0.52 & 0.080 & 0.080 & 0.080 & 0.080 & 0.080 & 0.080 \\
\hline Acephate & 1635 & 8 & 0.49 & 0.033 & 0.031 & 0.077 & 0.077 & 0.077 & 0.077 \\
\hline Methamidophos & 1640 & 8 & 0.49 & 0.057 & 0.033 & 0.120 & 0.120 & 0.120 & 0.120 \\
\hline Dichlorvos & 1638 & 7 & 0.43 & 0.055 & 0.014 & 0.130 & 0.130 & 0.130 & 0.130 \\
\hline Omethoate & 1628 & 6 & 0.37 & 0.068 & 0.070 & 0.930 & 0.930 & 0.930 & 0.930 \\
\hline Fenitrothion & 1638 & 6 & 0.37 & 0.033 & 0.016 & 0.100 & 0.100 & 0.100 & 0.100 \\
\hline Parathion & 1642 & 6 & 0.37 & 0.024 & 0.008 & 0.073 & 0.073 & 0.073 & 0.073 \\
\hline Phorate & 1649 & 6 & 0.36 & 0.006 & 0.003 & 0.017 & 0.017 & 0.017 & 0.017 \\
\hline Chlorpyrifos-methyl & 1598 & 5 & 0.31 & 0.020 & 0.005 & 0.080 & 0.080 & 0.080 & 0.080 \\
\hline Phosalone & 1616 & 5 & 0.31 & 0.047 & 0.025 & 0.152 & 0.152 & 0.152 & 0.152 \\
\hline Methidathion & 1629 & 5 & 0.31 & 0.076 & 0.044 & 0.170 & 0.170 & 0.170 & 0.170 \\
\hline Phosmet & 1575 & 3 & 0.19 & 0.013 & 0.013 & 0.013 & 0.013 & 0.013 & 0.013 \\
\hline Malathion & 1645 & 3 & 0.18 & 0.012 & 0.012 & 0.012 & 0.012 & 0.012 & 0.012 \\
\hline Pyridaphethione & 40 & 0 & 0 & - & - & - & - & - & - \\
\hline Diazinon & 6 & 0 & 0 & - & - & - & - & - & - \\
\hline Trichlorfon & 3 & 0 & 0 & - & - & - & - & - & - \\
\hline Quinalphos & 3 & 0 & 0 & - & - & - & - & - & - \\
\hline Phoxim & 3 & 0 & 0 & - & - & - & - & - & - \\
\hline
\end{tabular}

(1.60\%) tea samples contained two pesticides and 13 $(0.77 \%)$ contained three or more OPs.

Table 4 shows national consumption for three types of dry tea leaves according to the China National Nutrient and Health Survey (2002). Fermented tea showed the highest consumption level out of the three types of tea
$(9.83 \mathrm{~g} / \mathrm{d})$. Non-fermented tea and semi-fermented tea showed an average of $3.92(\mathrm{~g} / \mathrm{d})$ and $4.42(\mathrm{~g} / \mathrm{d})$, respectively. Fermented tea was consumed by the highest percentage of tea consumers (66\%); non-fermented tea and semi-fermented tea consumers accounted for 31.2 and $2.8 \%$, respectively.

Table 3 Summary of residue data of OP pesticides detected on tea samples analysed in China Monitoring Program

\begin{tabular}{|c|c|c|c|}
\hline \multirow{2}{*}{$\begin{array}{l}\text { Number of detected } \\
\text { pesticides in samples }\end{array}$} & Non-fermented tea & \multirow{2}{*}{$\begin{array}{l}\text { Semi-fermented tea } \\
\text { Number of detected samples }\end{array}$} & \multirow{2}{*}{$\begin{array}{l}\text { Fermented tea } \\
\text { Number of detected samples }\end{array}$} \\
\hline & Number of detected samples & & \\
\hline 0 & 1031 & 230 & 257 \\
\hline 1 & 84 & 33 & 12 \\
\hline 2 & 21 & 1 & 5 \\
\hline 3 & 4 & 1 & 0 \\
\hline 4 & 2 & 0 & 0 \\
\hline$\geq 5$ & 5 & 1 & 0 \\
\hline Total of detected samples & 116 & 36 & 17 \\
\hline Total of number of samples & 1147 & 266 & 274 \\
\hline
\end{tabular}


Table 4 Detailed consumption data of tea consumers in China

\begin{tabular}{lllllll}
\hline Tea category & \multicolumn{6}{c}{ Consumption of dry tea leaves (g/d) } \\
\cline { 2 - 7 } & Mean & P50 & P90 & P95 & P97.5 & Max \\
\hline Non-fermented green tea & 3.92 & 1.70 & 11.09 & 16.70 & 25.00 & 41.70 \\
Partly fermented oolong tea & 4.42 & 3.40 & 9.98 & 10.00 & 10.00 & 10.00 \\
Fermented black tea & 9.83 & 10.00 & 19.80 & 25.00 & 48.80 & 61.90 \\
\hline Pperen
\end{tabular}

$P$ percentile, Max maximum

\section{Dietary exposure assessment}

Table 5 shows the results of the distribution of exposure to OP residues from tea infusions for tea consumers in China. RPFs were calculated by BMD at $10 \% \mathrm{AChE}$ inhibition in the female rat brain, and CED at 20\% AChE inhibition in the female rat brain; the IC for OPs is methamidophos. Both types of critical effect doses were calculated, and the exposure distributions were extremely right-skewed, with estimates at P99.9, approximately more than two times higher than P99. This is because both food consumption and OP residue monitoring distributions were right-skewed, and the results of the exposure distribution were also right-skewed [49].

\section{Sensitivity analysis}

A sensitivity analysis was performed using @Risk software by calculating the Spearman rank-order correlation coefficient among the concentrations in the IC equipotent of OP residues in tea infusion, tea consumption and body weight. Figure 1 is the tornado diagram of sensitivity analysis of cumulative dietary exposure to OP residues from tea infusion. The absolute value of the correlation coefficient represents the ability of this variable to influence the cumulative dietary exposure to OP residues from tea infusion (Fig. 1). The results of the sensitivity analyses showed that the consumption of fermented tea was the most influential variable on cumulative dietary exposure to OP residues from tea

Table 5 Percentiles of distribution for dietary intake of Ops residues from tea infusion for tea consumers only in China

\begin{tabular}{lll}
\hline Percentiles of exposure & $\mathrm{OPs}^{\mathrm{a}}(\mu \mathrm{g} / \mathrm{kg} \mathrm{bw} / \mathrm{d})$ & $\mathrm{OPs}^{\mathrm{b}}(\mu \mathrm{g} / \mathrm{kg} \mathrm{bw} / \mathrm{d})$ \\
\hline Tea consumer & & \\
Mean & $0.02(0.02-0.02)^{\mathrm{c}}$ & $0.08(0.08-0.09)^{\mathrm{c}}$ \\
P50 & $0.01(0.01-0.01)$ & $0.05(0.05-0.05)$ \\
P90 & $0.04(0.04-0.06)$ & $0.17(0.17-0.25)$ \\
P95 & $0.06(0.05-0.06)$ & $0.25(0.24-0.25)$ \\
P97.5 & $0.08(0.07-0.08)$ & $0.33(0.32-0.35)$ \\
P99 & $0.11(0.10-0.12)$ & $0.46(0.44-0.50)$ \\
P99.9 & $0.25(0.20-0.30)$ & $1.08(0.85-1.23)$
\end{tabular}

${ }^{\mathrm{a} P P F s}$ calculated by $\mathrm{BMD}_{10}$, IC for OPs is methamidophos

${ }^{\mathrm{b}} \mathrm{RPFs}$ calculated by $\mathrm{CED}_{20}$, IC for OPs is methamidophos

cNumbers with brackets are the lower (2.5\%) and upper (97.5\%) bounds of the

$95 \%$ confidence interval of the corresponding percentiles of exposure infusion (correlation coefficient equal to 0.55). The second most influential variable was the concentration in methamidophos equivalents of OP residues in fermented tea infusions (correlation coefficient equal to 0.46).

\section{Discussion}

Dietary exposure assessment

Table 5 demonstrates that RPFs were calculated by $\mathrm{CED}_{20}$ in the female rat brain to estimate dietary exposure to OP residues from tea infusion was higher than the exposure results that were calculated by RPFs based on $\mathrm{BMD}_{10}$ in the female rat brain. The RPF approach assumes that the chemicals under consideration (1) act by a common mode of action, (2) differ only in potency and (3) do not interact [37]. If the log (dose)-response curves are parallel, the RPFs should be constant over the range of effects; RPFs were calculated by $\mathrm{BMD}_{10}$, and $\mathrm{CED}_{20}$ should be the same in theory. Compared to the two types of RPFs calculated by $\mathrm{BMD}_{10}$ and $\mathrm{CED}_{20}$ inhibition in the female rat brain after 21 days exposure to OPs, with methamidophos as the IC for OPs, the RPFs of all the OPs were almost identical, except for monocrotophos and omethoate (Fig. 2). Therefore, we chose the RPFs that were calculated by $C_{20}$ in the female rat brain to estimate the dietary exposure to OP residues from tea infusion in order to not underestimate the risk.

\section{Sensitivity analysis}

In a sensitivity analysis, the absolute value of the correlation coefficient of the consumption of fermented tea was highest of all. The higher absolute value of the correlation coefficient shows that the factor has the greater influence to the dietary exposure to OP residues from tea infusion.

But in our study, for tea consumers (especially extreme tea consumers), it may be hard to change one's habits with regard to consumption volume and types of tea consumed. Therefore, strengthening the management of OP residues in fermented tea would be effective in reducing OP exposure levels for tea consumers. These results may provide guidance for intervention measures for risk management.

\section{Dietary risk assessment}

In exposure assessments of OP residues in tea infusion, according to the regulatory threshold, the risk is at the upper tail of the exposure distribution (usually at P99.9) that is used by the US EPA [50]. The cumulative dietary exposures to OP residues in tea infusion were compared with the ARfD of methamidophos, $10 \mu \mathrm{g} / \mathrm{kg}$ bw/d. In this study, at P99.9, the cumulative dietary exposure to OP residues in tea infusion in methamidophos equivalents for Chinese tea consumers was $1.08 \mu \mathrm{g} / \mathrm{kg}$ bw/d, which accounted for $10.8 \%$ of the ARfD. In consideration of the 


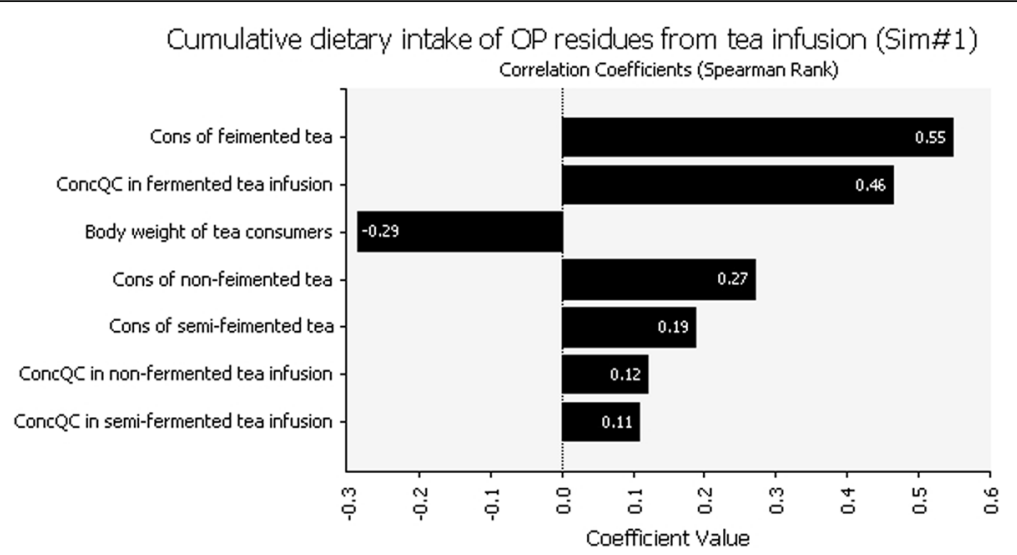

Fig. 1 Sensitivity analysis of cumulative dietary exposure to OP residues from tea infusion

most of the tea samples were undetectable, a worst case of the acute dietary intake of OPs residues from tea infusion was also calculated. Using of a deterministic assessment approach, tea samples with concentrations below the LOD were assumed to be LOD; the P99.9 of acute cumulative dietary intake of OPs residues from tea infusion were $5.85 \mu \mathrm{g} / \mathrm{kg}$ bw/d. This is the most conservative estimation of acute dietary cumulative intake of OP residues from tea infusion, which accounted for $58.5 \%$ of the ARfD.

It should be noted, however, that for tea consumers, the health risk of dietary exposure to OP residues should account for tea consumption as well as other dietary contributors (e.g. vegetables, fruits). A cumulative risk assessment study from Sun Jin-fang, which assessed dietary exposure to OP residues in China, also used the RPF approach; methamidophos was the IC, non-detected values were considered as LOD and the estimated means of cumulative dietary exposure (a total of 51 types of food including vegetables, fruits, staple foods) to OP residues for the general population and adults above 18 years old were 0.681 and $0.592 \mu \mathrm{g} / \mathrm{kg}$ bw/d, accounting for 6.81 and $5.92 \%$ of the ARfD [35]. In Sun's study, the vegetables were the largest contributor to OP residue intake in the general population; the tea contributed less than the vegetables for the general population [35]. This is mainly due to their low consumption in frequency and volume of tea among the general population.

According to dietary exposure to OP residues in Sun's study, considering OP residues from vegetables, fruits and other foods, it can be concluded that the level of

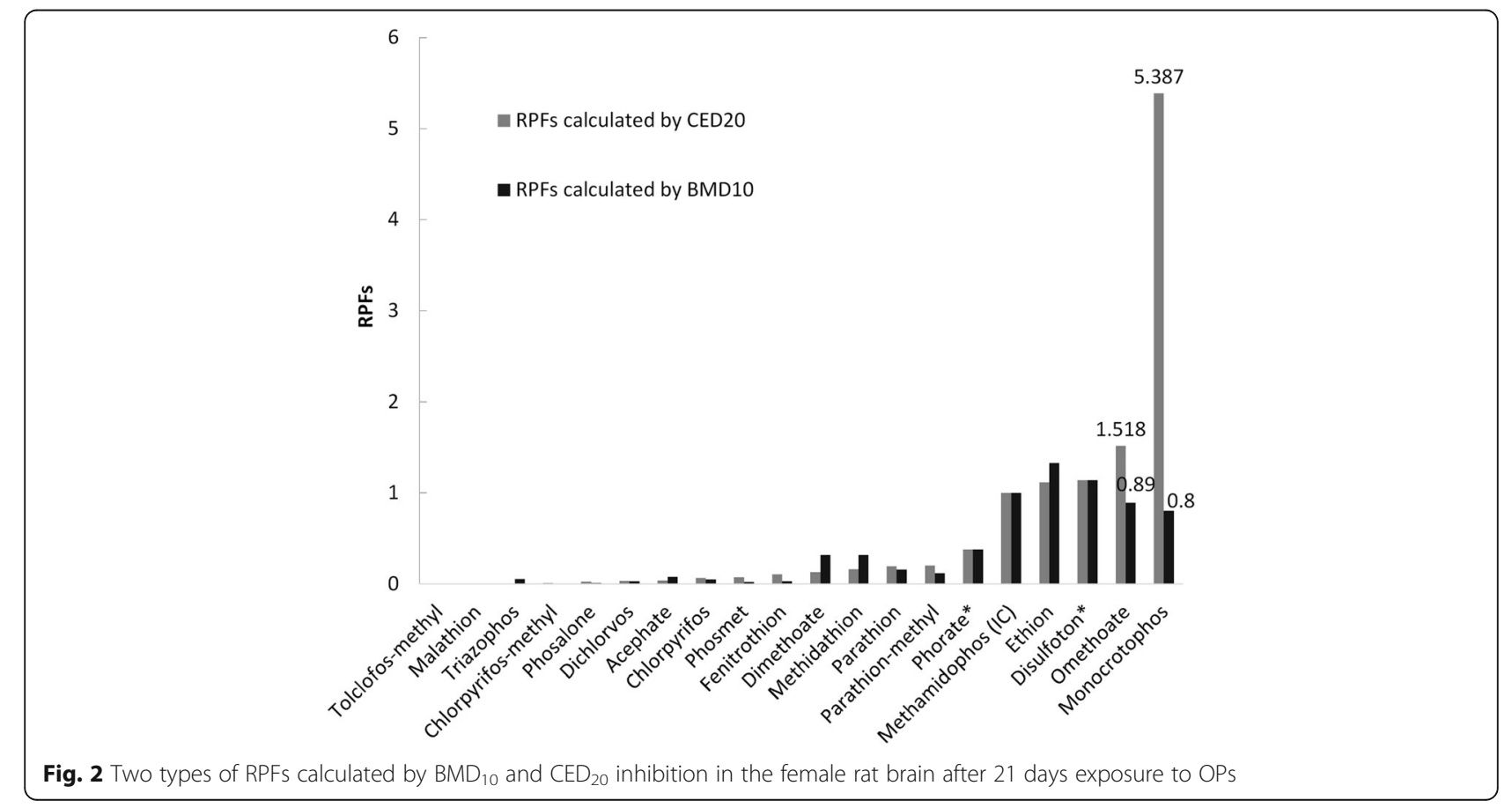


acute dietary exposure to OP residues in China for both general tea consumers and high tea consumers is safe. However, evidence suggests an association between low level and chronic exposure of OP pesticides and disorder of psychological and neurological development [51-53]. Therefore, it is necessary to strengthen the regulation of the OP pesticides used on tea in China to reduce the risk of chronic dietary exposure to OPs from tea infusion.

In addition, some uncertainties may have influenced the exposures estimated in the present study. First, we only focused on types of tea for which we had both concentration and consumption data; scented tea, brick tea and tea bags were not included, and this may have underestimated OP exposures for some tea consumers. Second, the tea consumption data used in this study were from the China National Nutrition and Health Survey of 2002, and tea consumption patterns and volume may have changed during the 15-year interval since the study. Meanwhile, there were 20 types of OPs detected in the tea samples in the Monitoring Program. Of these 20 types of pesticides, 7 have been banned for use in tea crops in China since 2005 due to their high toxicity. However, some banned pesticides may still be used in China. Therefore, it is important to implement regular monitoring of tea for pesticide residues and to pay more attention to the management of OP pesticides which are prohibited on tea in China.

\section{Conclusions}

This study provides estimates of cumulative dietary exposures to OPs from tea infusions using tea consumption data from the China National Nutrient and Health Survey (2002) and data on OP residue concentrations from the China National Monitoring Program (2013-2014). @Risk software was used to conduct the cumulative dietary exposure assessment in a probabilistic way. For tea consumers, the mean and P99.9 of cumulative dietary exposure to OP residues from tea infusions equalled 0.08 and $1.08 \mu \mathrm{g} / \mathrm{kg} \mathrm{bw} / \mathrm{d}$. When compared with the ARfD, $10 \mu \mathrm{g} / \mathrm{kg}$ bw/d for methamidophos, this accounts for 0.8 and $10.8 \%$ of the ARfD. Even when considering OP residues from vegetables, fruits and other foods, there are no health concerns based on acute dietary exposure to OP residues from tea infusion. However, it is necessary to strengthen the regulation of the OP pesticides used on tea in China to reduce the risk of chronic dietary exposure to OPs from tea infusion.

\section{Additional file}

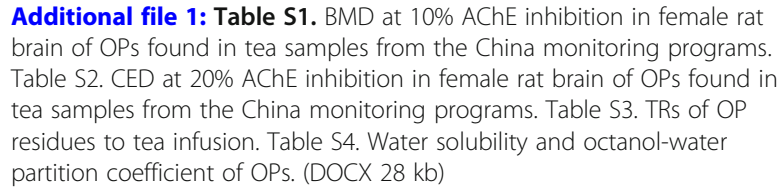

\section{Abbreviations}

ARfD: Acute reference dose; BMD: Benchmark dose; BW: Body weight;

CED: Critical effect dose; EPA: Environmental Protection Agency; GC-ECD: Gas chromatograph-electron-capture detector; GC-FID: Gas chromatograph-flame ionisation detector; GC-FPD: Gas chromatograph-flame photometric detection; GC-MS/MS: Gas chromatography-mass spectrometry; GC-NPD: Gas chromatograph-nitrogen-phosphorus detector; IC: Index compound; JMPR: Joint Meeting of Pesticide Residues; LOD: The limit of detection; NOAEL: No observed adverse effect levels; OP: Organophosphorus; RPF: Relative potency factor; TR: Transfer rate; UHPLC-MS/MS: Ultrahighperformance liquid chromatography-tandem mass spectrometry

\section{Acknowledgements}

We thank the National Institute for Nutrition and Health of Chinese Center for Disease Control and Prevention (CDC) and CDC in each province or district of China for providing the tea consumption and residue data.

\section{Funding}

This research was supported by the earmarked fund for Research of Hazard Identification Techniques for New Resource and Food Chemical Contaminants(2012BAK01B04) in National Sci-Tech Support Plan and China Food Safety Talent Competency Development Initiative: CFSA 523 Program.

\section{Availability of data and materials}

The datasets generated during and/or analysed during the current study are not publicly available due to a policy of the National Health and Family Planning Commission of the People's Republic of China but are available from the corresponding author on reasonable request.

\section{Authors' contributions}

PC designed the study and performed the statistical analyses of the tea consumption data, interpreted the data, and drafted the manuscript. DY and DJ performed the the statistical analyses of the residue data. JZ and ZL designed the study and checked the manuscript. HX designed the study and revised the manuscript. All authors read and approved the final manuscript.

Ethics approval and consent to participate

Not applicable.

\section{Consent for publication}

Not applicable.

\section{Competing interests}

The authors declare that they have no competing interests.

\section{Publisher's Note}

Springer Nature remains neutral with regard to jurisdictional claims in published maps and institutional affiliations.

\section{Author details \\ ${ }^{1}$ National Institute for Nutrition and Health, Chinese Center for Disease Control and Prevention, No 27, Nanwei Road, Xicheng District, Beijing 100050, China. ${ }^{2}$ Risk Assessment of Division One, China National Center for Food Safety Risk Assessment, No 37, Building 2, Guangqu Road, Chaoyang District, Beijing 100021, China.}

Received: 1 December 2017 Accepted: 4 February 2018

Published online: 14 February 2018

\section{References}

1. Chen L, Zhou ZX, Yang YJ. Genetic improvement and breeding of tea plant ( Camellia sinensis) in China: from individual selection to hybridization and molecular breeding. Euphytica. 2007;154:239-48.

2. Jain A, Manghani C, Kohli S, Nigam D, Rani V. Tea and human health: the dark shadows. Toxicol Lett. 2013;220:82-7.

3. Deka A, Vita JA. Tea and cardiovascular disease. Pharmacol Res. 2011;64:136-45.

4. Mukhtar H. Tea polyphenols for health promotion. Life Sci. 2007;81:519-33.

5. Yuan JM, Sun C, Butler LM. Tea and cancer prevention: epidemiological studies. Pharmacol Res. 2011;64:123-35. 
6. Li X, Zhang Z, Li P, Zhang Q, Zhang W, Ding X. Determination for major chemical contaminants in tea (Camellia sinensis) matrices: a review. Food Res Int. 2013;53:649-58.

7. Zeng X, Lu H, Campbell DE, Ren H. Integrated emergy and economic evaluation of tea production chains in Anxi. ChinaEcol Eng. 2013;60:354-62.

8. Wei G, Huang J, Yang J. The impacts of food safety standards on China's tea exports. China Econ Rev. 2012;23:253-64.

9. FAO (Food and Agriculture Organization). FAOSTAT online statistical service. 2010. http://www.fao.org/faostat/en/. Accessed 11 Feb 2018.

10. WTO (World Trade Organization). World Trade Organization SPS Information Management (SPSIMS). 2010. http://spsims.wto.org. Accessed 11 Feb 2018.

11. CTMA (China Tea Marketing Association). China's tea production and marketing report in 2014 and situation forecast in 2015. Tea World. 2015;6:50-9.

12. Kamel F, Hoppin JA. Association of pesticide exposure with neurologic dysfunction and disease. Environ Health Persp. 2004;112:950-8.

13. Li QYZL. Study on organophosphorus pesticides contamination on foodstuff and preventive measures. Industrial Health and Occupational Disease. 2005:31:260-3.

14. Liao HJ, Zhang XC, Li-Yuan HU, Zhong HC, Sun GY, Liu RF. Simultaneously detection of 10 kinds of organophosphorus pesticides residues in tea by gas chromatography. Chinese Journal of Food Hygiene. 2015;27:41-4.

15. Yang X, Xu D, Qiu J, Zhang H, Zhang YC, Dong AJ, Ma Y, Wang J. Simultaneous determination of 118 pesticide residues in Chinese teas by gas chromatography-mass spectrometry. Chem Pap. 2009;63:39-46.

16. Huang Z, Li Y, Chen B, Yao S. Simultaneous determination of 102 pesticide residues in Chinese teas by gas chromatography-mass spectrometry. JChromatogr B. 2007;853:154-62.

17. Huang $Z$, Zhang $Y$, Wang L, Ding L, Wang $M$, Yan $H$, et al. Simultaneous determination of 103 pesticide residues in tea samples by LC-MS/MS. J Sep Sci. 2009;32:1294-301.

18. Abd El-Aty AM, Choi JH, Rahman MM, Kim SW, Tosun A, Shim JH. Residues and contaminants in tea and tea infusions: a review. Food AdditContam Part A. 2014:31:1794-804.

19. Xue-Yuan WU, Sheng X, Fan W, Tang F, Yue YD. Extracting rate of three kinds of pesticide in MadeTea during brewing process and risk assessment on human health. J Tea Sci. 2007;27:141-6.

20. Chen ZM. Quality safety and environmental safety problems of tea industry in China. Quality and Safety of Agro-Products. 2011;3:5-7.

21. Chen H, Pan M, Pan R, Zhang M, Liu X, Lu C. Transfer rates of 19 typical pesticides and the relationship with their physicochemical property. J Agric Food Chem. 2015;63:723-30.

22. Feng J, Tang H, Chen D, Li L. Monitoring and risk assessment of pesticide residues in tea samples from China. Hum Ecol Risk Assess. 2015;21:169-83.

23. Hart A, Smith GC, Macarthur R, Rose M. Application of uncertainty analysis in assessing dietary exposure. Toxicol Lett. 2003;s140-141:437-42.

24. Sun JF, Liu P, Li CY, Li JX, Wang CN, Min J, et al. Probabilistic acute dietary exposure assessment of the Chinese population to cypermethrin residues. Food AdditContam Part A. 2011:28:869-76.

25. Kroes R, Muller D, Lambe J, Lowik MR, van Klaveren J, Kleiner J, et al. Assessment of intake from the diet. Food Chem Toxicol. 2002:40:327-85.

26. Caldas ED, Tressou J, Boon PE. Dietary exposure of Brazilian consumers to dithiocarbamate pesticides-a probabilistic approach. Food Chem Toxicol. 2006;44:1562-71.

27. Boon PE, Hvd V, Klaveren JD. Validation of a probabilistic model of dietary exposure to selected pesticides in Dutch infants. Food AdditContam part A. 2003;20:36-49.

28. EFSA(European Food Safety Authority).Opinion of the Scientific Panel on plant protection products and their residues to evaluate the suitability of existing methodologies and, if appropriate, the identification of new approaches to assess cumulative and synergistic risks from pesticides to human health with a view to set MRLs for those pesticides in the frame of Regulation (EC) 396/2005. 2008. http://onlinelibrary.wiley.com/doi/10.2903/..efsa.2008.705/epdf. Accessed 11 Feb 2018.

29. Pang GF, Fan CL, Zhang F, Li Y, Chang QY, Cao YZ, et al. High-throughput GC/MS and HPLC/MS/MS techniques for the multiclass, multiresidue determination of 653 pesticides and chemical pollutants in tea. J AOAC Int. 2011:94:1253-96.

30. Wang J, Chow W, Leung D. Applications of LC/ESI-MS/MS and UHPLC/QqTOF-MS for the determination of 141 pesticides in tea. J AOAC Int. 2011;94: 1685-714.
31. Boon PE, Van der Voet H, Van Raaij MT, Van Klaveren JD. Cumulative risk assessment of the exposure to organophosphorus and carbamate insecticides in the Dutch diet. Food Chem Toxicol. 2008;46:3090-8.

32. Seed J, Brown RP, Olin SS, Foran JA. Chemical mixtures: current risk assessment methodologies and future directions. Regul Toxicol Pharmacol. 1995;22:76-94.

33. Gallagher SS, Rice GE, Scarano LJ, Teuschler LK, Bollweg G, Martin L. Cumulative risk assessment lessons learned: a review of case studies and issue papers. Chemosphere. 2015;120:697-705.

34. US EPA. Revised organophosphorus pesticide cumulative risk assessment. 2002. https://www.epa.gov/pesticide-science-and-assessing-pesticide-risks/ cumulative-assessment-risk-pesticides. Accessed 11 Feb 2018.

35. Sun JF. Cumulative risk assessment of dietary exposure to organophosphorus pesticides in China. Southeast University. 2011;

36. Sui $H X$, Zhang L, Wu PG, Song Y, Yong L, Yang DJ, et al. Concentration of di(2-ethylhexyl) phthalate (DEHP) in foods and its dietary exposure in China. INT J HYG ENVIR HEAL. 2014;217:695-701.

37. Bosgra S, van der Voet H, Boon PE, Slob W. An integrated probabilistic framework for cumulative risk assessment of common mechanism. chemicals in food: an example with organophosphorus pesticides. Regul Toxicol Pharmacol. 2009;54:124-33.

38. US EPA. Preliminary cumulative hazard and dose-response assessment for organophosphorus pesticides:determination of relative potency and points of departure for cholinesterase inhibition. 2001. https://archive.epa.gov/ scipoly/sap/meetings/web/pdf/relativepotency.pdf. Accessed 11 Feb 2018.

39. Van RMTM, Ossendorp BC, Slob W, Pieters MN. Cumulative exposure to cholinesterase inhibiting compounds: a review of the current issues and implications for policy. 2007. http://www.rivm.nl. Accessed 11 Feb 2018

40. Ozbey A, Uygun U. Behaviour of some organophosphorus pesticide residues in peppermint tea during the infusion process. Food Chem. 2007: 104:237-41.

41. Wang J, Cheung W, Leung D. Determination of pesticide residue transfer rates (percent) from dried tea leaves to brewed tea. J Agric Food Chem. 2014;62:966-83.

42. Jaggi S, Sood C, Kumar V, And SDR, Shanker A. Leaching of pesticides in tea brew. J Agr Food Chem. 2001;49:5479-83.

43. Manikandan N, Seenivasan S, Ganapathy MNK, Muraleedharan NN, Selvasundaram R. Leaching of residues of certain pesticides from black tea to brew. Food Chem. 2009;113:522-5.

44. Cho SK, Abd El-Aty AM, Rahman MM, Choi JH, Shim JH. Simultaneous multidetermination and transfer of eight pesticide residues from green tea leaves to infusion using gas chromatography. Food Chem. 2014;165:532-9.

45. Chen Z, Wan H. Factors affecting residues of pesticides in tea. Pest Manag Sci. 1988;23:109-18.

46. Wan $\mathrm{H}, \mathrm{Xia} \mathrm{H}, \mathrm{Chen} \mathrm{Z}$. Extraction of pesticide residues in tea by water during the infusion process. Food Addit Contam. 1991;8:497-500.

47. Nagayama T. Behavior of residual organophosphorus pesticides in foodstuffs during leaching or cooking. J Agr Food Chem. 1996;44:2388-93.

48. FAO. Pesticide residues in food. 2002:2002. http://www.fao.org/fileadmin/ templates/agphome/documents/Pests_Pesticides/JMPR/Reports_1991-2006/ Report_2002.pdf. Accessed 11 Feb 2018

49. Claeys WL, Voghel SD, Schmit JF, Vromman V, Pussemier L. Exposure assessment of the Belgian population to pesticide residues through fruit and vegetable consumption. Food Addit Contam part A. 2008:25:851-63.

50. EPA USA. Choosing a percentile of acute dietary exposure as a threshold of regulatory concern. 2000. https://www.epa.gov/pesticide-science-andassessing-pesticide-risks/choosing-percentile-acute-dietary-exposurethreshold. Accessed 11 Feb 2018

51. Ross SJM, Brewin CR, Curran HV, Furlong CE, Abraham-Smith KM, Harrison V. Neuropsychological and psychiatric functioning in sheep farmers exposed to low levels of organophosphate pesticides. Neurotoxicol Teratol. 2010;32:452-9.

52. Burns CJ, Mclntosh LJ, Mink PJ, Jurek AM, Li AA. Pesticide exposure and neurodevelopmental outcomes: review of the epidemiologic and animal studies. J Toxicol Environ Health B Crit Rev. 2013;16:127-283.

53. Maria Teresa MQ, Lucero BA, Lglesias VP, Munoz MP, Cornejo CA, Achu E, et al. Chronic exposure to organophosphate (OP) pesticides and neuropsychological functioning in farm workers: a review. Int J Occup Environ Health. 2016;22:68-79. 